\title{
Emissão foliar, relações iônicas e produção do coqueiro irrigado com água salina
}

\author{
Leaf emission, ionic relations and production of coconut irrigated with saline water
}

\author{
Miguel Ferreira Neto ${ }^{\mathrm{I}}$ Hans Raj Gheyi ${ }^{\mathrm{II}^{*}}$ Pedro Dantas Fernandes ${ }^{\mathrm{II}}$ \\ José Simplício de HolandaIII Flávio Favaro Blanco ${ }^{\mathrm{IV}}$
}

\section{RESUMO}

A necessidade de uso de águas salinas na agricultura é crescente, devido à pressão sobre águas de boa qualidade, principalmente para consumo humano. Com este objetivo, foram estudados os efeitos de quatro níveis de condutividade elétrica da água de irrigação (CEa: 0,1; 5,0; 10,0 e 15,0dS $\mathrm{m}^{-1}$ ), obtidos mediante adição de $\mathrm{NaCl}$ sobre o desenvolvimento do coqueiro (Cocos nucifera L.) cv. "Anão Verde”, com 3,5 anos de idade. O experimento foi conduzido em blocos casualizados, em solo arenoso, irrigado por microaspersão, no município de Parnamirim-RN, no período de janeiro de 2000 a março de 2001. A salinidade da água aumentou os intervalos de emissão foliar e de inflorescência e o número de flores femininas, bem como os teores de Na e de Cl na folha número 14, acompanhado de relações antagônicas entre $\mathrm{Na}-\mathrm{Ca}, \mathrm{Na}-\mathrm{K}$ e Cl- $\mathrm{N}$ e sinergismo entre $\mathrm{Na}-\mathrm{Mg}$, mas sem manifestar sintomas visuais de efeitos tóxicos. Os teores ótimos de $\mathrm{Na}$ e $\mathrm{Cl}$ na folha 14 foram, respectivamente, 0,207 e 0,580\%.

Palavras-chave: Cocos nucifera L., nutrição, condutividade elétrica.

\section{ABSTRACT}

The necessity to use saline waters in agriculture has increased due to pressure on good quality water, principally, for human consumption. With this objective, the effects of four levels of electrical conductivity (0.1, 5.0, 10.0 and 15.0dS $\left.\mathrm{m}^{-1}\right)$ of irrigation water obtained by addition of $\mathrm{NaCl}$ were studied on the development of 3.5 years old coconut (Cocos nucifera L.) $c v$. 'Anão Verde'. The experiment was conducted in a sandy soil adopting a completely randomized block design and micro sprinkler irrigation system in the municipality of Parnamirim RN, Brazil, during the period of January, 2000 to March, 2001. The salinity of water increased the interval of leaf emission and inflorescences and the number of female flowers per inflorescence as well as the contents of $\mathrm{Na}$ and $\mathrm{Cl}$ in leaf 14, accompanied by antagonism between $\mathrm{Na}-\mathrm{Ca}, \mathrm{Na}-\mathrm{K}$ and $\mathrm{Cl}-\mathrm{N}$, and synergism between $\mathrm{Na}-\mathrm{Mg}$ but without any visual symptoms of toxic effects. The optimum levels of $\mathrm{Na}$ and $\mathrm{Cl}$ in 14th leaf were found to be 0.207 and $0.580 \%$.

Key words: Cocos nucifera L., nutrition, electrical conductivity.

\section{INTRODUÇÃO}

O coqueiro é cultivado em mais de 80 países, constituindo-se em importante fruta tropical, tanto para consumo in natura como para fins industriais, com mais de 360 modalidades de aproveitamento. A área colhida no Brasil, em 2004, atingiu 280.835ha, gerando 1,9 bilhões de frutos (ANUÁRIO ESTATÍSTICO DO BRASIL, 2004), 5,5\% da produção mundial, o que o classifica como quarto maior produtor de coco. Vale salientar que a produtividade brasileira é a segunda maior do mundo $\left(10,8 \mathrm{Mg} \mathrm{ha}^{-1}\right)$, sendo inferior apenas à do Peru (15,7 Mg ha-1) (FAO, 2003). No Brasil, a cultura do coqueiro é de grande importância socioeconômica, principalmente para o Nordeste, de onde provêm quase $74 \%$ da produção nacional de coco.

Com a mesma tendência de outras culturas, está aumentando o cultivo de coqueiro irrigado, faltando, entretanto, um maior respaldo técnicocientífico, pela carência de resultados de pesquisa nas

\footnotetext{
IDepartamento de Ciências Vegetais, Universidade Federal Rural do Semi-Árido (UFERSA), 59625-900, Mossoró, RN, Brasil

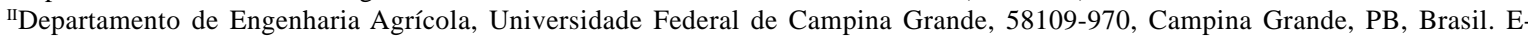
mail: hans@deag.ufcg.edu.br.*Autor para correspondência.

IIIEMBRAPA, Empresa de Pesquisa Agropecuária do Estado do Rio Grande do Norte, Natal, RN, Brasil.

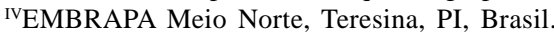


condições edafoclimáticas do Brasil (FERREIRA et al., 1997). Nos plantios comerciais sob irrigação no Brasil, predomina a variedade de coqueiro “Anão Verde”, cuja exigência hídrica varia entre 103 e 173L por planta dia ${ }^{-1}$, no terceiro ano de cultivo (MIRANDA et al., 1999).

$\mathrm{Na}$ agricultura, atividade com maior consumo hídrico, torna-se necessário o uso de águas de qualidade marginal, entre elas as salinas, visando a aumentar a oferta de água de boa qualidade para outros usos mais nobres. Um dos casos é no cultivo do coqueiro, espécie admitida como tolerante à salinidade, devido à sua área de dispersão natural predominar na costa marítima. Os solos utilizados para o cultivo de coqueiro no litoral são arenosos e profundos; o excesso de sais provenientes das irrigações com águas salinas pode ser lixiviado durante o período chuvoso, diminuindo os seus efeitos sobre a planta e o solo (FERREIRA et al., 1997; FERREIRA NETO et al., 2002). MANCIOT et al. (1979) relatam ser prática antiga o uso de água do mar na irrigação de coqueiros em Java, Índia e Colômbia.

Em estudos recentes, realizados por FERREIRA NETO et al. (2002), foi verificado que águas salinas aplicadas durante o período de frutificação do coqueiro “Anão Verde” alteram o desenvolvimento das plantas e melhoram a qualidade da água de coco, principalmente por aumentar o teor de sólidos solúveis, embora diminuam o tamanho e o volume de água do fruto.

Este trabalho teve como objetivo estudar os efeitos da salinidade da água de irrigação sobre o desenvolvimento do coqueiro “Anão Verde”, em termos de emissão foliar, relações iônicas na folha e produção de frutos.

\section{MATERIAL E MÉTODOS}

O estudo foi realizado na Fazenda Experimental da Empresa de Pesquisa Agropecuária do Rio Grande do Norte (EMPARN), em Parnamirim, RN (546' S, 3512' O), em um pomar de coqueiro (Cocos nucifera L.), cultivar “Anão Verde”, com 3,5 anos de idade na fase inicial de produção, durante o período de janeiro de 2000 a março de 2001. O solo da área é classificado como Neossolo quartzarênico (EMBRAPA, 1999), com alto teor de areia $\left(956 \mathrm{~g} \mathrm{~kg}^{-1}\right)$, baixa capacidade de retenção de água $\left(10 \mathrm{kPa}=50 \mathrm{~g} \mathrm{~kg}^{-1}\right)$, baixos valores de CTC (1,74 $\left.\mathrm{cmol}_{\mathrm{c}} \mathrm{kg}^{-1}\right), 16,4 \mathrm{mg} \mathrm{kg}^{-1} \mathrm{de}$ $\mathrm{P}, \mathrm{pH}=5,9$ e $0,3 \mathrm{dS} \mathrm{m}^{-1}$ de condutividade elétrica do extrato de saturação.

O espaçamento das plantas era triangular (7,5 x 7,5 x 7,5m) e foi feita uma irrigação antes do início do experimento com água de manancial superficial (lagoa) com $0,1 \mathrm{dS} \mathrm{m}^{-1}$ de condutividade elétrica.
Foram estudados os efeitos de quatro níveis de salinidade da água de irrigação (CEa): N1=0,1; $\mathrm{N} 2=5,0 ; \mathrm{N} 3=10,0$ e $\mathrm{N} 4=15,0 \mathrm{dS} \mathrm{m}^{-1}$, no delineamento experimental de blocos casualizados, com cinco repetições, sendo a parcela constituída de quatro plantas. Foi adicionado $\mathrm{NaCl}$ à água da lagoa, a fim de se obter as águas de diferentes salinidades (N2, N3 e N4), sendo preparadas todos os dias e armazenadas em caixas de fibra de vidro, com capacidade de $3.000 \mathrm{~L}$, após ser conferida a condutividade elétrica. Das caixas, a água era bombeada, abastecendo linhas de microaspersores (vazão média de $58 \mathrm{~L} \mathrm{~h}^{-1}$ ), aplicandose, diariamente, $120 \mathrm{~L}$ por planta. A irrigação era suspensa nos dias em que a chuva excedia $10 \mathrm{~mm}$. Durante o período experimental, a temperatura média foi de $27,4^{\circ} \mathrm{C}$; a umidade relativa do ar oscilou entre $77,4 \%$ em dezembro/2000 e 92,8\% em julho/2000; os menores índices de precipitação pluvial ocorreram nos meses de outubro/2000 a fevereiro/2001 (0,0mm em outubro e janeiro; $11,5 \mathrm{~mm}$ em novembro; $18,5 \mathrm{~mm}$ em dezembro e 6,8mm em fevereiro).

Durante todo o período experimental, foram adotadas práticas de adubação, de controle de pragas e eliminação de folhas secas e de restos florais, conforme recomendações de FERREIRA et al. (1997) para a cultura. A adubação de cobertura teve periodicidade semestral, com esterco de frango (15L planta $^{-1}$ ) e $2 \mathrm{~kg}_{\text {planta }}{ }^{-1}$ do composto químico à base de fósforo (FOSMAG), de composição (\%): $\mathrm{P}_{2} \mathrm{O}_{5}-18,0$; Ca - 14,0; Mg - 3,5; S - 10,0; Zn - 0,65; B - 0,15; Cu - 0,18. Os fertilizantes à base de $\mathrm{N}$ (uréia: $40 \mathrm{~g} \mathrm{planta}^{-1}$ ) e de $\mathrm{K}$ (KCl: 30 g planta $^{-1}$ ) foram aplicados, semanalmente, via fertirrigação.

No início da aplicação dos tratamentos, em janeiro de 2000, foi feita a primeira contagem de folhas vivas em todas as plantas. As contagens seguintes foram realizadas em abril (início do período chuvoso), agosto (final das chuvas), novembro/2000 e a última em janeiro de 2001.

O florescimento foi avaliado anotando-se o intervalo entre florações e contando-se o número de flores femininas por inflorescência. A produção foi avaliada pelo número total de frutos colhidos por planta, através de colheitas mensais, no estádio apropriado para consumo da água de coco. Considerando-se que a diferenciação floral ocorre cerca de cinco meses antes do florescimento, foi considerada a produção a partir da quinta inflorescência após início dos tratamentos, a qual foi emitida em maio de 2000. A última colheita foi realizada em março de 2001, quando foram colhidos os frutos da nona inflorescência.

Para a análise foliar, por ocasião da última colheita de frutos (março/2001), foram coletados, em 
duas plantas por parcela, folíolos da região mediana da folha número 14 , geralmente indicada para avaliação do estado nutricional das plantas (FERREIRA et al., 1997). Foram analisados os teores de N, K, Ca, Mg, Na e Cl (MALAVOLTA et al., 1997) e obtidas as relações $\mathrm{Cl} / \mathrm{N}, \mathrm{Na} / \mathrm{Ca}, \mathrm{Na} / \mathrm{K}$ e $\mathrm{Na} / \mathrm{Mg}$.

Os resultados foram analisados através de teste $\mathrm{F}$ e regressão polinomial, em nível de $5 \%$ de significância, com transformação dos dados de número de frutos em $\sqrt{x}$ (FERREIRA, 2000).

\section{RESULTADOS E DISCUSSÃO}

Relacionando-se o número de folhas emitidas $(\mathrm{Y})$ com os níveis de CEa (X), foi obtida a equação: $\mathrm{Y}=22,354+0,1188 \mathrm{X}-0,0215 \mathrm{X} 2\left(\mathrm{r}^{2}=0,96 * *\right)$. Em geral, as plantas se desenvolveram bem, em termos de emissão foliar, pois, no período de um ano, mesmo no nível mais alto de salinidade $\left(\mathrm{CEa}=15 \mathrm{dS} \mathrm{m}^{-1}\right)$, foram emitidas, em média, 19,4 folhas. Esse número é superior às 18 folhas que um coqueiro “Anão” adulto emite em condições ambientais favoráveis (FERREIRA et al., 1997). Ainda pela equação de regressão, o número máximo de folhas (22,5 folhas) corresponderia à CEa de $2,76 \mathrm{dS} \mathrm{m}^{-1}$, havendo redução da emissão foliar, em relação ao tratamento irrigado com água de CEa de $0,1 \mathrm{dS} \mathrm{m}^{-1}$, só em níveis de CEa superiores a 5,5dS m²Mesmo com alta salinidade (15dS $\left.\mathrm{m}^{-1}\right)$, a redução na emissão foliar foi pequena (13,7\%). Em termos relativos, o número de folhas emitidas neste tratamento foi superior ao que foi registrado por SILVA JUNIOR et al. (2002), em condições de sequeiro, variando de 11 a 15 folhas.

A redução do número de folhas emitidas sob estresse salino foi decorrente do aumento do intervalo de emissão foliar (Y), registrando-se efeito linear dos níveis de CEa $\left(\mathrm{Y}=22,179+0,4663 \mathrm{X} ; \mathrm{r}^{2}=0,97^{* *}\right)$, com atraso de, aproximadamente, 0,47 dias na emissão de folha por aumento unitário na CEa acima de $0,1 \mathrm{dS} \mathrm{m}^{-1}$. Como conseqüência disso, ao aumentar a salinidade da água, elevou-se, linearmente, o número de folhas mortas $\left(Y=2,2546+0,129 X ; r^{2}=0,89 * *\right)$, chegando a ser $84,8 \%$ maior no tratamento de $15 \mathrm{dS} \mathrm{m}^{-1}$, em relação ao de $0,1 \mathrm{dS} \mathrm{m}^{-1}$. O aumento foi de $5,7 \%$ por incremento unitário da salinidade, em relação ao tratamento de $0,1 \mathrm{dS}$ $\mathrm{m}^{-1}$. Com o aumento da concentração de sais, o potencial osmótico da solução do solo se torna mais negativo, requerendo das plantas maior dispêndio energético para absorção de água (TESTER \& DAVENPORT, 2003). Assim, sob estresse salino, as plantas atrasam a emissão de folhas e desativam parte de sua área foliar, na tentativa de reduzir a perda de água por transpiração, diminuindo, consequentemente, a assimilação de carbono e a produção.
Não houve efeito significativo da salinidade no número de flores femininas nas quatro primeiras inflorescências, ocorridas entre janeiro (início de aplicação dos tratamentos) e abril de 2000. A quinta inflorescência foi emitida em maio de 2000, aumentando a partir daí o número de flores femininas na ordem de emissão das inflorescências, com a elevação da salinidade da água de irrigação (Figura 1). O efeito da salinidade sobre o número de flores femininas da quinta à oitava inflorescências foi quadrático e linear na nona emissão. Segundo FERREIRA et al. (1997), a diferenciação floral ocorre por volta de 11 meses antes de sua respectiva emissão. Assim, no presente caso, as primeiras inflorescências devem ter sido diferenciadas em dezembro/1999 (período de baixa pluviosidade e evapotranspiração alta), sendo as condições de temperatura e de umidade relativa menos favoráveis ao coqueiro.

Com base nas equações de regressão, notase que na quinta inflorescência o maior número de flores femininas foi de 12,58, correspondente à CEa de 9,13dS $\mathrm{m}^{-1}$, aumentando nas sucessivas ordens de floração: 30,4 flores a 10,32dS m ${ }^{-1}$ na sexta; 66,8 flores a $11,26 \mathrm{dS} \mathrm{m}^{-1}$ na sétima e 119,4 flores a $11,76 \mathrm{dS} \mathrm{m}^{-1}$ na oitava inflorescência. Portanto, com a acumulação temporal de sais no solo, a planta aumentou o número de flores femininas, uma reação típica de organismos vivos sob condições de estresse abiótico, na tentativa de garantir a preservação da espécie (XIONG \& ZHU, 2001). O aumento do número de flores femininas resultou em efeito linear da salinidade na última inflorescência analisada, com aumento de 8,6 flores femininas por incremento unitário da CEa (Figura 1). REMISON et al. (1988) relatam que Ramanandan observou, também, aumento do número de flores femininas com o incremento da concentração de cloreto de sódio na água de irrigação.

Além de interferir nas flores femininas, a salinidade aumentou, linearmente, o intervalo entre inflorescências, com acréscimo no tempo de 0,1 dia por aumento unitário da CEa, acima de $0,1 \mathrm{dS} \mathrm{m}^{-1}$, com base na seguinte equação de regressão: $\mathrm{Y}=25,209$ + 0,1237X $\left(\mathrm{r}^{2}=0,92 *\right)$. Em média, ocorreu atraso de uma semana na emissão de inflorescências (Y) quando se usou água com $15 \mathrm{dS} \mathrm{m}^{-1}$ de condutividade elétrica, em relação à CEa de $0,1 \mathrm{dS} \mathrm{m}^{-1}$.

Apesar da salinidade da água ter aumentado o número de flores femininas, não houve correspondência desse aumento sobre a produção de frutos, uma vez que o efeito dos tratamentos sobre a produção não foi significativo. Assim, a salinidade da água de irrigação e talvez alguns outros fatores interferiram na fisiologia das plantas, afetando a 


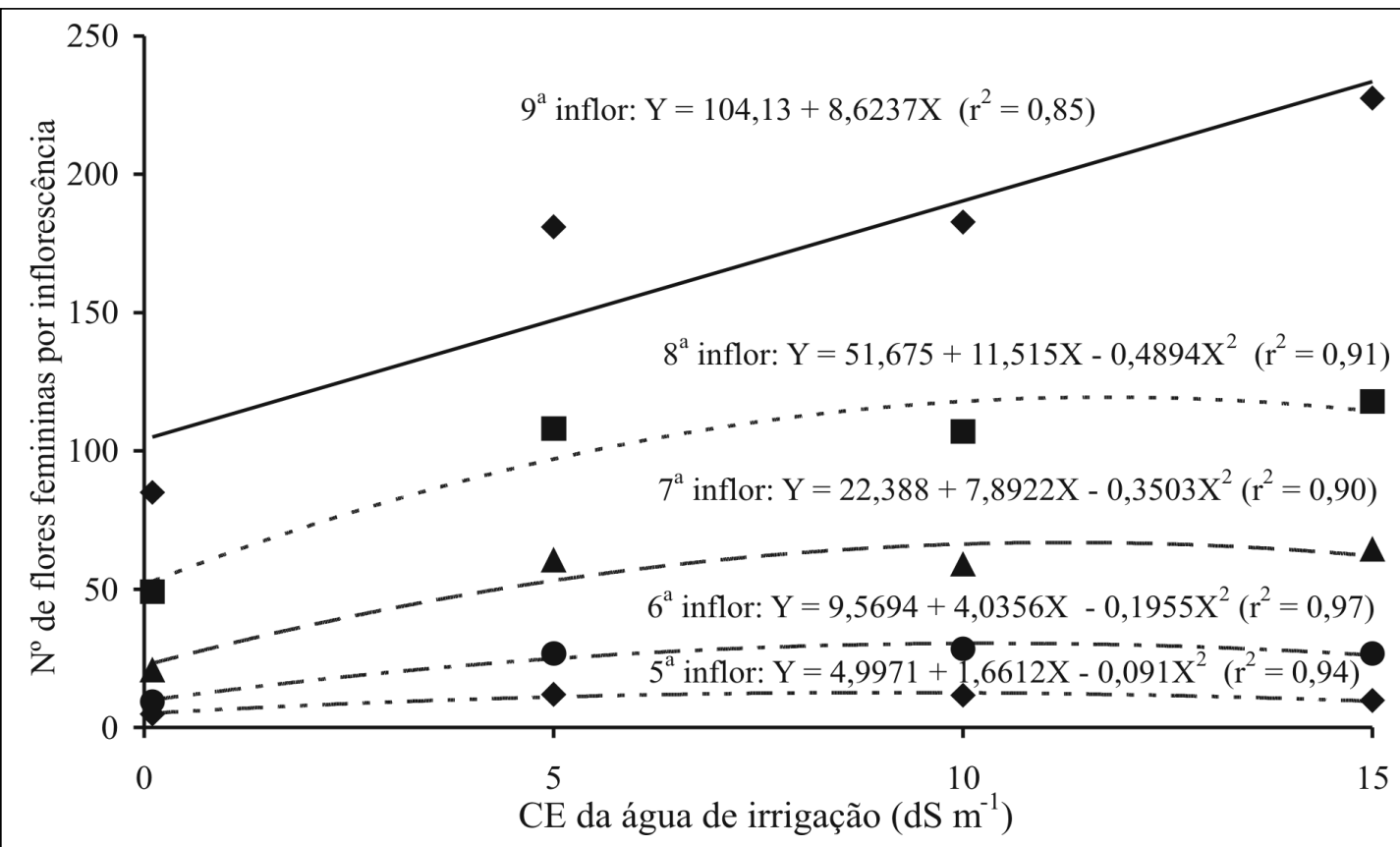

Figura 1 - Número médio de flores femininas por inflorescência, a partir do florescimento ocorrido em maio de 2000 (5 $5^{\text {a }}$ inflorescência).

fertilidade das flores femininas, uma vez que as mesmas não resultaram em formação de frutos. O abortamento dessas flores foi decorrência de algum fator fisiológico e/ou bioquímico, provavelmente devido à acumulação de sódio e/ou cloro em concentração elevada (Figura 2). Sendo a nutrição do coqueiro favorecida pelo íon Cl- (Von UEXKULL, 1972; SOUZA et al., 1997), é provável que o efeito prejudicial tenha sido causado pela acumulação de $\mathrm{Na}$, embora não tenham surgido nas folhas quaisquer sintomas visuais.

Neste trabalho, em base de cinco colheitas, a produção média por planta $\mathrm{ano}^{-1}$ foi equivalente a 56,1, 54,2, 60,5 e 40,4 frutos nos tratamentos de 0,1, 5,0, 10 e $15 \mathrm{dS} \mathrm{m}^{-1}$, respectivamente. Portanto, a produção foi, praticamente, constante nos três primeiros tratamentos e, no nível mais alto de salinidade $\left(15 \mathrm{dS} \mathrm{m}^{-1}\right)$, o número de frutos colhidos, em média, foi $29 \%$ menor. Mesmo assim, neste tratamento, a produção foi quase três vezes superior aos 15 frutos por planta ano ${ }^{-1}$ relatados por FERREIRA et al. (1997), em condições de sequeiro. Esses mesmos autores se reportam à produção de 60 frutos por planta ano-1 em coqueiros sob irrigação, com 4 anos de idade.

Os teores de $\mathrm{N}$, K e de Ca na planta diminuíram com o incremento da condutividade elétrica e aumentaram os de $\mathrm{Mg}, \mathrm{Cl}$ e $\mathrm{Na}$ (Figura 2), podendose constatar relações antagônicas entre $\mathrm{Cl}$ e N, Na e K e Na e Ca e sinergismo entre Na e Mg. REMISON et al.
(1988), estudando os efeitos de salinidade em plântulas de coqueiro gigante, observaram reduções nos teores de N, K e Ca, porém sem alterações nos teores de Mg. Considerando-se ser o $\mathrm{N}$ absorvido, preferencialmente, na forma nítrica $\left(\mathrm{NO}_{3}{ }^{-}\right)$(EPSTEIN \& BLOOM, 2006), à primeira vista, poderia ser um efeito competitivo com o ânion cloreto, fato também observado por REMISON et al. (1988), na medida em que aumentou a concentração desse íon na água de irrigação. Com base nas equações de regressão, houve incremento da relação $\mathrm{Cl} / \mathrm{N}$ de 0,20 para 0,60 (Figura

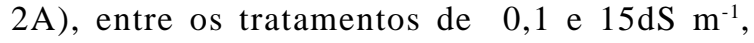
respectivamente, mais pela elevação de cloreto (180,9\% entre esses níveis) que devido à diminuição de $\mathrm{N}$, a qual foi de apenas 7,9\%. Embora na presença de $\mathrm{NaCl}$ tenha sido menor a concentração de $\mathrm{N}$ nas plantas, não foi observada nenhuma evidência de limitação nutricional desse nutriente nas plantas.

Além de certo antagonismo, o aumento do teor de cloreto deveu-se à maior absorção desse íon, decorrente de sua alta concentração na solução do solo, nos tratamentos mais salinos. Há de se considerar, ainda, a essencialidade do cloreto para o coqueiro, o qual, conforme Von UEXKULL (1972), é o íon diretamente envolvido na abertura e no fechamento dos estômatos. REMISON et al. (1988) e FERREIRA et al. (1997) relatam que o crescimento e desenvolvimento do coqueiro são favorecidos com a presença de cloreto na adubação. 


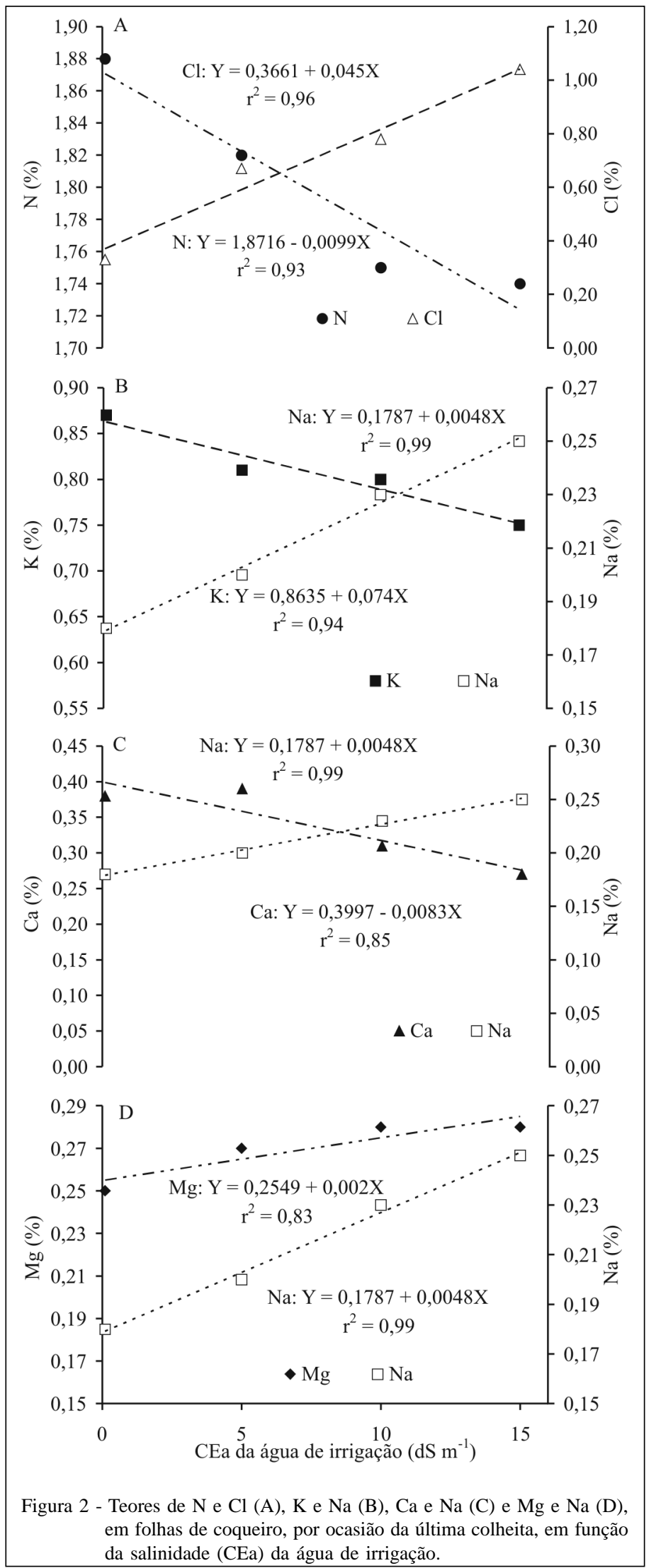

A acumulação de sódio nas plantas aumentou 39,9\%, entre os tratamentos de 0,1 e $15 \mathrm{dS} \mathrm{m}^{-1}$. Mesmo em altos níveis de salinidade, o coqueiro consegue manter um balanço iônico favorável entre cátions, sem maiores efeitos sobre o desenvolvimento das plantas. Os efeitos de inibição competitiva entre Na e K (Figura 2B) e Na e Ca (Figura 2C) não causaram prejuízos às plantas, por suas concentrações se situarem em níveis toleráveis, comparando-os com dados da literatura (FERREIRA et al., 1997). O teor de $\mathrm{K}$ diminuiu 12,8\% no nível mais salino (15dS $\mathrm{m}^{-1}$ ) em relação a $0,1 \mathrm{dS} \mathrm{m}^{-1}$ e a relação $\mathrm{Na} / \mathrm{K}$ aumentou de 0,21 para 0,33. Conforme EPSTEIN \& BLOOM (2006), o mecanismo de seletividade de absorção iônica, especificamente relacionado a $\mathrm{Na}$ e K, varia entre grupos de plantas; pelos resultados ora apresentados, pode-se dizer que o coqueiro possui alta eficiência na seletividade de absorção de íons (Na e K). TESTER \& DAVENPORT(2003)eEPSTEIN \& BLOOM (2006) citam que uma característica de tolerância das plantas à salinidade é a habilidade de manter a relação $\mathrm{Na} / \mathrm{K}$ em valores inferiores a um. No presente trabalho, o valor máximo atingido foi de 0,33 , com uso da água mais salina $\left(15 \mathrm{dS} \mathrm{m}^{-1}\right)$, uma evidência de ser o coqueiro anão tolerante à salinidade.

Os efeitos da salinidade sobre os níveis de Ca na planta foram maiores que sobre os de K, com decréscimo de $31 \%$ no nível mais alto de salinidade (15dS $\mathrm{m}^{-1}$ ). Portanto, a inibição do sódio sobre o cálcio foi maior devido à maior concentração do sódio na solução do solo e, conseqüentemente, à maior absorção, por ser monovalente e de menor raio iônico (0,95 A) em relação ao cálcio $(0,99 \AA \AA)$. A relação $\mathrm{Na} / \mathrm{Ca}$ se elevou de 0,45 , em plantas irrigadas com água de CE $0,1 \mathrm{dS} \mathrm{m}^{-1}$, para 0,91 em 15dS m ${ }^{-1}$ (Figura 2C), com acréscimo de aproximadamente $102 \%$. O Ca é um nutriente relacionado diretamente com a permeabilidade seletiva da plasmalema (EPSTEIN \& BLOOM, 2006). Pelos resultados, infere-se não ter sido afetada essa importante função com o aumento da concentração de Na nas células, pois, 
mesmo em nível mais alto da salinidade da água, a relação $\mathrm{Na} / \mathrm{Ca}$ manteve-se próxima a um.

Dentre os fatores relacionados com a habilidade das plantas em tolerar excesso de sais, incluem-se a manutenção de uma relação mais favorável entre Na e Ca, sem resultar em sintomas de deficiência deste último, e a capacidade de manter níveis adequados de $\mathrm{K}$, em condições de elevada concentração de Na no solo (TESTER \& DAVENPORT, 2003). Neste trabalho, apesar de um incremento considerável do cloreto na planta, o aumento da concentração de $\mathrm{Na}$ na água de irrigação e, conseqüentemente, na solução do solo, não resultou em quaisquer desordens nutricionais; as mudanças observadas nos teores e nas relações iônicas não podem ser consideradas desordens nutricionais. Algumas variáveis (fertilidade de flores, produção de frutos, número de folhas emitidas) decresceram com o aumento da salinidade, como mecanismos de adaptação das plantas à salinidade (TESTER \& DAVENPORT, 2003). Assim, o efeito se limitou apenas em pequenas variações das relações iônicas, em níveis tolerados pelas plantas, mantendo um equilíbrio iônico favorável, mesmo irrigando-se com água de alta salinidade (CEa = $15 \mathrm{dS} \mathrm{m}^{-1}$ ). Provavelmente, o coqueiro tenha uma boa capacidade de ajuste osmótico, compartimentalizando o excesso de Na no vacúolo celular, um dos mecanismos de tolerância à salinidade (TESTER \& DAVENPORT, 2003).

Na relação entre Na e Mg (Figura 2D), foi observado sinergismo, aumentando os teores de ambos com o incremento da CEa da água de irrigação. O aumento de $\mathrm{Mg}$, porém, foi menor, da ordem de $0,7 \%$, por unidade de CEa, comparativamente aos 2,68\% de $\mathrm{Na}$, resultando em relação $\mathrm{Na}+\mathrm{Mg}^{2+}$ de 0,70 em $0,1 \mathrm{dS}$ $\mathrm{m}^{-1}$ e de $0,88 \mathrm{em} 15 \mathrm{dS} \mathrm{m}^{-1}$. Não se encontrou na literatura referência a sinergismo entre $\mathrm{Na}$ e $\mathrm{Mg}$, ocorrendo, entretanto, esse fenômeno entre $\mathrm{Mg}^{2+}$ e $\mathrm{Ca}^{2+}$ (WHITE \& BROADLEY, 2003), com a elevação de Ca no citossol estimulada pela absorção de Mg. Ao contrário, geralmente é encontrada inibição competitiva entre os dois elementos, como observado em maracujazeiro (SOARES et al., 2002). As explicações para o aumento da absorção de Mg podem envolver o cálcio, por ser menor o raio iônico de magnésio (0,65 A). Segundo FERREIRA (2002), cálcio e magnésio não têm a mesma seletividade de troca iônica, devido à menor energia de adsorção de magnésio, favorecendo sua absorção, o que deve ter se refletido nos dados obtidos neste trabalho. Pode-se, ainda, levar em consideração, para explicar a maior absorção de Mg, o fato de ter sido utilizado o FOSFOMAG na adubação, cuja solubilidade aumenta em meio salino.
Estudaram-se, ainda, as relações entre teores de $\mathrm{Na}^{+}$e de $\mathrm{Cl}^{-}$na folha 14 e número total de frutos colhidos (Figura 3), constatando-se ser benéfica para a planta a concentração de sódio de $0,207 \%$, resultando em 62,2 frutos planta ${ }^{-1}$ (7,89 em dados transformados). No caso do cloro, a concentração foi $180 \%$ mais alta $(0,580 \%)$ e a produção praticamente igual (61,5 ou 7,84 frutos planta ${ }^{-1}$, em dados transformados). Portanto, o coqueiro “Anão Verde” tolera cloro em proporção mais de duas vezes superior à de sódio. Como nas folhas não se observou qualquer sintoma de queimadura ou mancha, esses níveis não devem ser confundidos com toxicidade, mas sim para fins de nutrição e de produção.

\section{CONCLUSÕES}

A salinidade da água de irrigação aumenta a senescência das folhas, o intervalo entre emissão foliar e o de inflorescência. Apesar de aumento do número de flores femininas, não houve incremento correspondente na produção de frutos do coqueiro “Anão Verde”, devido ao abortamento dessas flores. Ocorre acumulação de $\mathrm{Na}$ e de $\mathrm{Cl}$ em folhas de coqueiro com incremento da salinidade da água de irrigação, sem sintomas visuais de toxicidade na planta, sendo acompanhada de inibição competitiva entre $\mathrm{Cl} / \mathrm{N}, \mathrm{Na}$ /

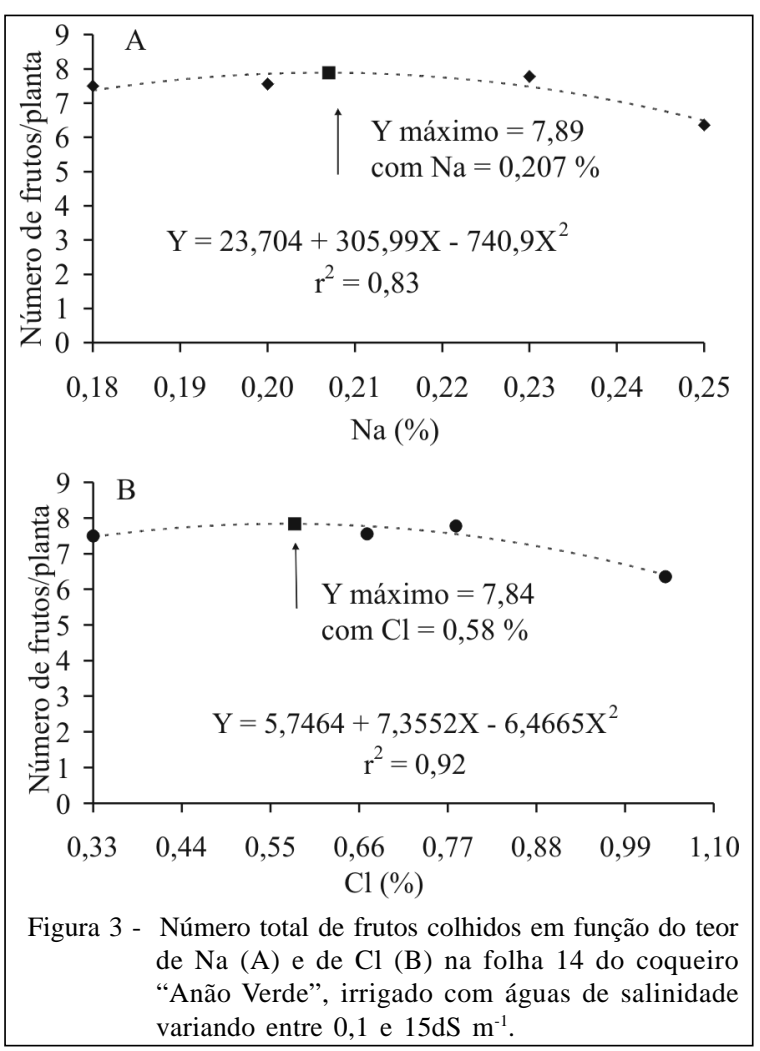


$\mathrm{K}, \mathrm{Na} / \mathrm{Ca}$ e de sinergismo entre $\mathrm{Na} / \mathrm{Mg}$. Os teores de $\mathrm{Na}$ e $\mathrm{Cl}$ na folha 14 que proporcionam produção máxima de frutos são de 0,207 e 0,580\%, respectivamente. As produções obtidas com águas de irrigação de condutividade elétrica até $10 \mathrm{dS} \mathrm{m}^{-1}$ são aproximadas àquelas do cultivo com água de baixa salinidade.

\section{REFERÊNCIAS}

ANUÁRIO ESTATÍSTICO DO BRASIL. Rio de Janeiro: IBGE, 2004. V.62.

EMBRAPA. Centro Nacional de Pesquisa de Solos (Rio de Janeiro, RJ). Sistema brasileiro de classificação de solos. Brasília: Embrapa-SPI/Embrapa-CNPS, 1999. 412p

EPSTEIN, E.; BLOOM, A.J. Nutrição mineral de plantas: princípios e perspectivas. 2.ed. Londrina: Planta, 2006. 403p.

FAO. Food and Agricultural Organization of United Nations. World agriculture toward 2000: a FAO study. London: Bellhaven, 2003. 338p.

FERREIRA, J.M.S.M. et al. A cultura do coqueiro no Brasil. Aracaju: Embrapa Tabuleiros Costeiros, 1997. 350p.

FERREIRA, P.A. Manejo de água-planta em solos salinos. Viçosa: UFV, 2002. 110p.

FERREIRA, P.V. Estatística experimental aplicada à agronomia. Maceió: UFAL, EDUFAL, FUNDEPES, 2000. $422 p$

FERREIRA NETO, M. et al. Qualidade do fruto verde de coqueiro em função da irrigação com água salina. Revista Brasileira de Engenharia Agrícola e Ambiental, v.6, p.69-75, 2002.
MALAVOLTA, E. et al. Avaliação do estado nutricional das plantas: princípios e aplicações. Piracicaba: Associação Brasileira para Pesquisa da Potassa e do Fosfato, 1997. 281p.

MANCIOT, R. et al. Mineral nutrition and fertilization of the coconut around the world. Oléagineux, v.34, p.499-515, 1979.

MIRANDA, F.R. et al. Desenvolvimento e precocidade de produção do coqueiro Anão (Cocos nucifera L.) sob diferentes regimes de irrigação. Agrotropica, v.11, p.71-76, 1999.

REMISON, S.U. et al. Effect of salinity on nutrient content of the leaves of coconut seedlings. Plant and Soil, v.109, p.135138, 1988.

SILVA JÚNIOR, C.D. et al. Aplicação de água salina no desenvolvimento e comportamento fisiológico do coqueiro. Revista Brasileira de Engenharia Agrícola e Ambiental, v.6, p. 39-44, 2002

SOARES, F.A.L. et al. Water salinity and initial development of yellow passion fruit. Scientia Agricola, v.59, p.491-497, 2002.

SOUZA, C.A.S. et al. O nutriente cloro em três palmeiras cultivadas. Agrotrópica, v.9, p.83-98, 1997.

TESTER, M.; DAVENPORT, R. Na+ tolerance and Na+ transport in higher plants. Annals of Botany, v.91, p.503527, 2003.

von UEXKULL, H.R. Response of coconut to (potassium) chloride in the Philippines. Oléagineux, v.27, n.1, p.13-19, 1972.

WHITE, P.J.; BROADLEY, M.R. Calcium in plants. Annals of Botany, v.92, p.487-511, 2003.

XIONG, L.; ZHU, J.K. Abiotic stress signal transduction in plants: molecular and genetic perspectives - review. Physiologia Plantarum, v.112, p.152-166, 2001. 